\title{
As another M\&A wave begins: three keys to success
}

\begin{tabular}{|r|l|}
\hline Journal: & Strategy \& Leadership \\
\hline Manuscript ID & SL-01-2021-0008 \\
\hline Manuscript Type: & Research Paper \\
\hline Keywords: & $\begin{array}{l}\text { M\&A best practice, M\&A valuation, post-merger integration, big-three } \\
\text { human factors of M\&A, Oxford M\&A Insights Project, M\&A leadership }\end{array}$ \\
\hline \multicolumn{2}{|l}{} \\
\hline
\end{tabular}




\section{As another M\&A wave begins: three keys to success}

\section{Timothy J. Galpin}

Tim Galpin is Senior Lecturer of Strategy and Innovation at the Saïd Business School, University of Oxford (timothy.galpin@sbs.ox.ac.uk). He is the author of Winning at the Acquisition Game: Tools, templates, and best practices across the M\&A process, (Oxford University Press, 2020).

The most recent merger and acquisitions "wave" starting after the financial crisis in 2009 was brought to an abrupt halt in the first half of 2020 by Covid-19 lockdowns around the globe. However, as acquirers eyed buying opportunities and sellers desperate for cash were put on the market, the second half of 2020 saw the highest deal pace since 2007. [1] Predictably, as the Covid-19 crisis recedes, struggling firms will be bought by bargain hunters and suffering industries will consolidate, giving rise to another wave of M\&A transactions. But buyers beware! There is ample evidence that M\&A creates significant post-deal performance issues for acquiring "buy-side" firms. However, new research shows that effectively managing three processes of acquisitions can have an outsized beneficial impact on M\&A success.

\section{When M\&A goes wrong}

For example, a broad analysis of 2,500 deals found that more than 60 percent destroyed shareholder value. [2] Recent high-profile examples of value destroying transactions include:

- Bayer's ill-fated \$63bn U.S. acquisition of Monsanto. Since completing the deal in 2018, Bayer's market value is now half of where it was in 2015 when the deal was completed. [3]

- Occidental Petroleum's $\$ 55 \mathrm{bn}$ acquisition of Anadarko. After acquiring Anadarko in 2019, Occidental Petroleum's market capitalization has fallen from about $\$ 42 \mathrm{bn}$ on the day the Anadarko deal completed to roughly $\$ 12 \mathrm{bn}$ now, and the firm has cut its dividend by almost 90 percent, their first dividend cut since 1991. [4]

\section{Three keys to M\&A success}

Poor results from M\&A have been attributed to a variety of management missteps both pre- and post-deal. [5] However, among the myriad aspects of transactions, recent research has identified three mission-critical tasks that stand out as being vital to creating M\&A success:

Process 1: Accurately valuing targets.

Process 2: Proficiently managing post-merger integration.

Process 3: Skillfully addressing the "big-three human factors" of M\&A. 


\section{Process 1: Accurate target valuation}

A survey of 1000 corporate and private equity executives identified accurately valuing the target as one of the top two most important issues within management's control that create M\&A success or failure. [6] For example, during the bidding war for Anadarko with rival Chevron, Occidental shareholder and activist investor Carl Icahn raised a very public concern that Occidental was grossly overvaluing the transaction, stating he believed the deal to be "fundamentally misguided and hugely overpriced," even attempting to take the company to court to prevent the deal from taking place. [7] It turns out he was correct. Occidental eventually outbid Chevron and acquired Anadarko for $\$ 55 \mathrm{bn}$ in 2019 . Subsequently, Occidental has cut its dividend by 85 percent and its shares have fallen a staggering 80 percent from their peak 2018 value. [8]

Several factors have been identified that contribute to buyers inaccurately valuing a target company during their pre-deal assessment and subsequently paying too much for their acquisitions including: high stock prices due to financial market exuberance, herding behavior creating too many buyers chasing too few available assets, senior management's over-optimism about its ability to achieve projected gains, large compensation windfalls due to executive bonuses and stock tied to growth and CEO hubris caused by past fortunate success. [9]

\section{Mitigating the potential for buyers to overpay}

There are several best practices when conducting M\&A valuation that can help prevent buyers from overpaying:

- Using multiple valuation methods - Applying multiple valuation methods to build overlapping ranges of projections results in a more realistic valuation of what the target is worth to a potential buyer (see "The four most common valuation methods.")

\section{The four most common target valuation methods}

1. Comparable company analysis ("public comps" or simply "comps"): Evaluating other, similar companies' current valuation metrics, determined by market prices and applying them to the company being valued.

2. Discounted cash flow analysis (DCF): Valuing a company by projecting its future cash flows and then using the net present value (NPV) method to "discount" the future value of the firm's cash flows back to today's value.

3. Precedent transaction analysis (M\&A comps): Examining historical prices for completed M\&A transactions involving similar companies to get a range of valuation multiples. This analysis attempts to arrive at a "control premium" paid by an acquirer to have control of the business.

4. Leverage buyout/"ability to pay" analysis (LBO): Valuing a company by assuming the acquisition of the company would be a "leveraged buyout," which uses a significant amount of borrowed capital to fund the purchase, and assuming a required rate of return for the purchasing entity. 
The results of these four methods can be displayed side-by-side in a bar chart known as a "Football field analysis," providing a more complete perspective of a target's value. Although no one of the four methods is considered best, the DCF model is often cited as the most "scientific" because various assumptions about future cost and revenue "synergies" resulting from the transaction can be tested.

- Applying realistic assumptions - Management is often overly optimistic about its ability to achieve potential cost or revenue deal synergies. Moreover, in a typical company valuation, 50 to 80 percent of the discounted cash flow value stems from the horizon (terminal) value, so selecting a realistic terminal value is crucial. [10]

- Involving the "Operators" - Too often valuation models are constructed solely by members of the corporate finance team or the bankers representing the acquirer. Although these individuals are skilled in financial modeling, they often do not know the particulars of the firm's operations. "Operators" -- those who will be responsible for running the business after the acquisition -- bring much more detailed and realistic knowledge of the cost and revenue synergies that are actually achievable from a potential transaction. Consequently, firms that exclude the operators from the valuation process do so at their peril.

- Assigning a "Devil's Advocate" - Avoid the tendency for "group think" by assigning someone on the valuation team to identify potentially unrealistic assumptions and to make the case for realistic expectations of what is more likely achievable.

- Incorporating "extreme shock" - Build alternate valuation models that account for extreme variations of the "base case" model, identifying the impacts and projected probabilities of economic downturns or "black swan" events.

\section{Process 2: Proficiently managing post-merger integration (PMI)}

While accurate target valuation was one of the two most important issues that creates M\&A success or failure, as identified by the 1000 dealmakers surveyed, well-managed post-merger integration (PMI) was the other.

Well-managed post-merger integration requires a multi-staged and cross-functional process that decreases the likelihood that implementation difficulties will arise in the subsequent post-transaction stages. Combining M\&A experience with a systemized and documented end-to-end M\&A process -- including pre- and post-deal activities -- has been found to improve transaction success. An analysis of 228 U.S. bank mergers taking place over a ten-year period from 1997 to 2007 found that combining two key factors, experience and a clear M\&A methodology, enhances deal performance. [11] The first factor, which the researchers call "tacit knowledge," consists of M\&A know-how and exists largely in the minds of executives, managers and employees. The second factor, which they term "codified knowledge," consists of written procedures that a company articulates in the form of routines or norms that can be repeated from deal to deal and guide actions and decision-making throughout the M\&A process, both pre- and post-transaction close. Despite evidence that a systematized M\&A process improves deal success, other research has found that almost two-thirds (60 percent) of surveyed 
executives indicated their firms do not have a comprehensive end-to-end M\&A process model.

As part of a codified M\&A process, a firm's approach to post-merger integration should be skillfully managed according to a standard and repeatable method. The first step of which is to map implementation priorities, enabling management to address the highest priority integration initiatives first. Integration priorities should be those with the most impact on capturing projected deal value including the largest areas of cost savings and revenue enhancement. Examples of firms that have built and incorporated a model M\&A process into their deal-making include GE, Cisco and Woodward, with each of these firms being commonly identified in the business press as realizing substantial value from their acquisitions. [12]:

- Steering Committee - A small team of three to five executives who provide postmerger integration sponsorship, implementation oversight, impasse resolution, investment decisions and implementation plans' go/no-go decisions.

- PMI Program Management Team - Responsibilities of this team include project planning and management, facilitating daily coordination across functional PMI Task Forces, progress and results tracking and on-going post-merger integration communications.

- PMI Task Forces - There is typically one Task Force per area of functional integration -- Operations, IT, HR and Marketing -- plus a cultural alignment team, each staffed by representatives from the combining firms. Each Task Force designs functional post-merger integration plans, coordinates with other Task Forces and identifies key functional implementation milestones and due dates.

Successful post-merger integration planning and execution also requires an "agile project management" approach, which includes on-going coordination between Task Forces facilitating regular issues identification, rapid decision making and continuous course corrections. Without systematic and efficient coordination within and between PMI Task Forces, chaos becomes more likely, implementation quickly loses momentum, and the integration effort grinds to a standstill. Each of the PMI teams -Steering Committee, Program Management team and Task Forces -- must work in concert to keep the planning and implementation process on track. Weekly review meetings between the Task Force heads, and lead by the PMI Program Management Team, should:

- Review progress from the previous week.

- Identify any obstacles encountered.

- Address cross-functional coordination required.

- Identify decisions needed from the Steering Committee essential to post-merger integration progress. 
Agile post-merger integration incorporates five core principles:

- Apply an 80/20 rule for decision-making - Managers spend 80 percent of their time trying to get 20 percent more information, therefore " 80 percent information" is sufficient to decide, implement and adjust.

- Push decisions down to the PMI Task Forces - Allow as many decisions as is practicable to be made by the PMI Task Forces. But establish escalation protocols for more "material" decisions such as large capital expenditures or major personnel impacts, which should be raised to the Steering Committee for resolution within 72 hours. The longer decision-making takes, the greater the chance of losing momentum.

- Stagger implementation - To build momentum, implement "quick wins," publicize them and congratulate the successful Task Forces, then address medium- and longer-term implementation actions.

- Simplify tracking and reporting - Develop and install a streamlined post-merger integration tracking "dashboard," including one-page summaries for each Task Force and for the overall PMI program.

- Apply PMI learning to future planning and on-going execution - Continuous customer and employee feedback is essential to adapt post-merger integration actions as needed.

\section{Process 3: Skillfully addressing the "big-three human factors" of M\&A}

In addition to accurate target valuation and well-managed PMI, another survey of 124 executives across 21 industries identified the "big three human factors" that either enhance or hinder successful M\&A [13]:

1. Communication.

2. Retention and re-recruitment -- regaining employees' commitment to the success of the combined organization -- of key talent.

3. Assessing and integrating corporate cultures.

Communication. Successful M\&A communication starts with identifying key internal and external stakeholders, including middle-management and employees across various functions and geographies in both of the combining organizations. External stakeholders include analysts, the press, communities in which the firms operate and regulators. Next, the aims of communicating to each set of stakeholders should be determined. For example, the goal of communications to management and employees can be to gain their buy-in to implement key post-merger integration actions. Whereas communications to analysts and the press can be used to create awareness of the progress made toward achieving key milestones and targets. Finally, communication methods, frequency and responsibilities must be laid out. A comprehensive M\&A communications plan includes the delivery methods that will be used -- electronic, faceto-face and video -- the frequency of communications to each stakeholder group and roles and responsibilities for the design and delivery of key messages by communications department, PR firm, senior- or middle-management. 
Retention and re-recruitment. Robust talent retention and re-recruitment plans initially entail identifying key talent, defined as individuals and groups who are essential to retain and re-recruit during a transitionary period and those required for long-term value creation. Next, various "motivators" - what key stakeholders would like from the newly combined organization - should be identified. This may be more money, but frequently it is something else -- a new role, a new location or different equipment. The next step is choosing and delivering retention and re-recruitment actions, designating who is responsible for delivering each action and the timing of delivery. Finally, in case certain key talent intends to leave, a back-up plan of how to fill the gap created should be drafted and ready to implement.

Assessing and integrating cultures. A pragmatic cultural assessment and integration plan includes comparing the organizational environments of each firm, then implementing a combined "organizational architecture" designed to "nudge" desired cultural behaviors among the merged workforces. [14] The event management and ticketing company Eventbrite offers an example of creating value by effectively addressing the people issues faced during M\&A. Through seven acquisitions between 2013 and 2018, including four cross-border transactions, the firm has grown to more than 900 employees in 12 offices around the world and a valuation estimated at more than $\$ 1 \mathrm{bn}$. When assessing potential acquisitions, founder and CEO Julia Hartz indicates that 70 percent of her concerns are about talent -- "it has to feel like a cultural fit" -- 20 per cent is about strategic fit and 10 percent is about finances. With a strong belief that "talent can make or break a deal" Ms. Hartz will walk away from a potential acquisition if the culture fit is not right. [15]

\section{The "human factors" of M\&A need much more attention}

The Oxford M\&A Insights Project published in 2020 surveyed 337 "C-Suite" executives across 31 industries, spanning over 40 countries, about the critical pitfalls and best practices across the M\&A process. [16] Respondents represented views from the "buyside" (acquirer) and "sell-side" (seller), pre- and post-transaction activities, with experience on multiple deals. Respondents indicated their firms are motivated to undertake deals for a variety of reasons including industry consolidation, cost reduction, access to new geographic markets, to new customer segments, to new products and services, to new industries, and to talent. The other main findings of the Project are:

- Companies generally perform the pre-deal stages of M\&A well - Pre-deal activities account for a majority (59 percent) of the M\&A activities respondents said their firms do well - due diligence, setting a clear M\&A Strategy, targeting companies with "strategic fit," negotiation, valuation and addressing legal and regulatory requirements.

- However, firms need to improve their "post-deal" M\&A capabilities - Post-deal activities the M\&A activities companies could perform better include operations and technology integration, communication, cultural analysis and integration, talent 
management and retention, senior leadership involvement and measurement and reporting.

- The "human factors" of M\&A need much more attention - Just a small percentage of respondents said that their firms perform M\&A communication, talent retention and re-recruitment and cultural analysis and integration well (see Exhibit 1 ). The importance of addressing the human factors of M\&A is reinforced by openended comments from respondents:

- "Communicate, communicate, communicate to manage stakeholder expectations."

- "Culture and bias were the biggest factors inhibiting a successful M\&A."

- "Personalities overcame mathematics in the process."

\section{Exhibit 1: The "Big three human factors" of M\&A (Oxford study)}

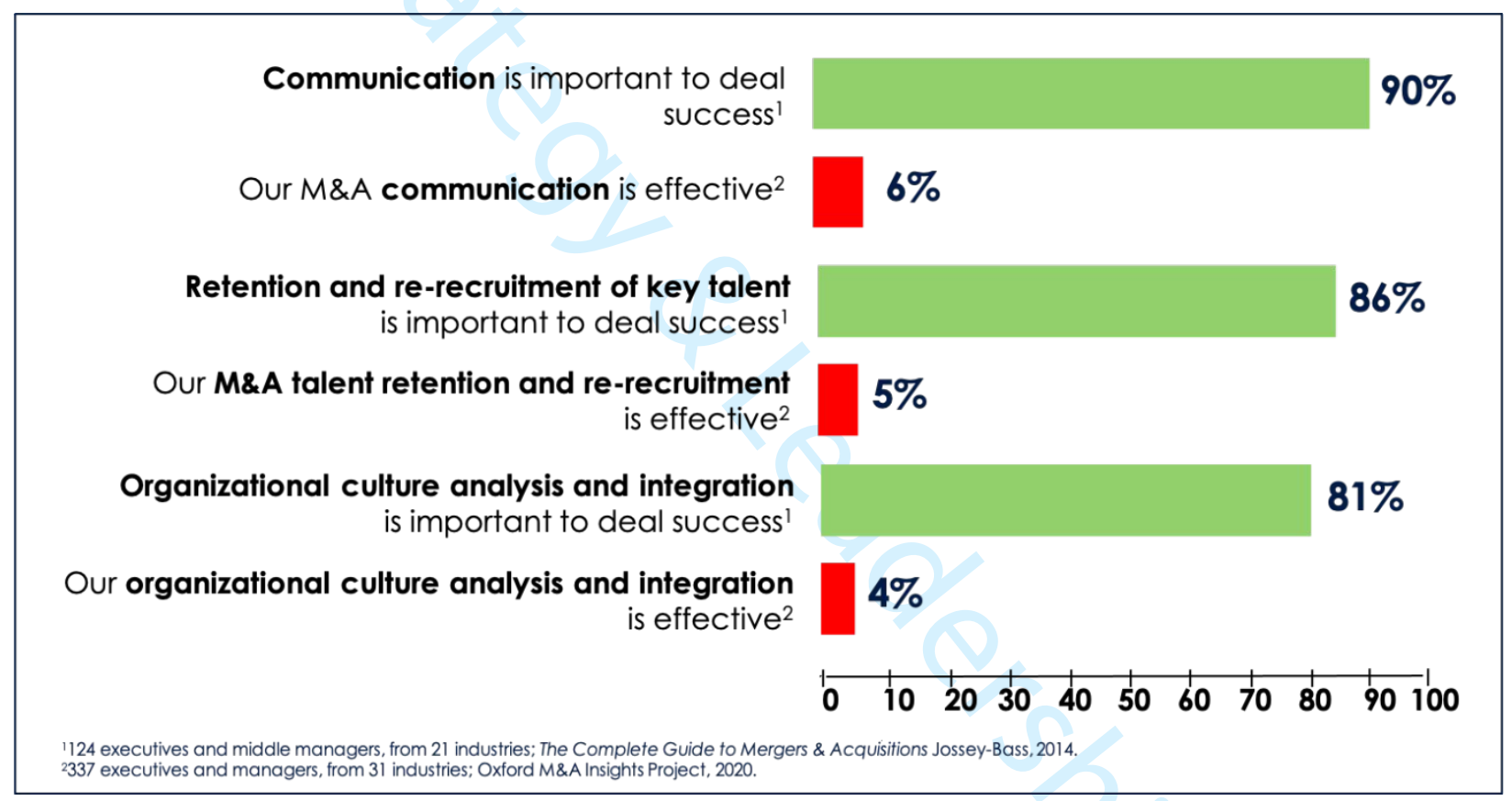

\section{Takeaways}

Business resurgence in the wake of the Covid-19 pandemic will likely give rise to another wave of M\&A around the globe. Corporate leaders can expect the difficulty realizing the projected value of transactions to continue. Accurately valuing targets, proficiently managing post-transaction integration and skillfully addressing the "big three human factors" of M\&A are three key means of making acquisitions work.

[Quotes]

"Predictably, as Covid-19 recedes, struggling firms will be bought by bargain hunters and suffering industries will consolidate, giving rise to another wave of M\&A transactions." 
"New research shows that effectively managing three processes of acquisitions can have an outsized beneficial impact on M\&A success."

"Effective post-merger integration is managed best through a temporary 'integration program infrastructure."'

"Each of the PMI teams -- Steering Committee, Program Management team and Task Forces -- must work in concert to keep the planning and implementation process on track."

"Robust talent retention and re-recruitment plans initially entail identifying key talent, defined as individuals and groups who are essential to retain and re-recruit during a transitionary period and those required for long-term value creation."

'Various 'motivators' - what key stakeholders would like from the newly combined organization - should be identified."

Notes

1. Mergermarket (2021). "2020 global M\&A report with financial league tables," Mergermaket, https://www.mergermarket.com/info/2020-global-ma-reportfinancial-league-tables (accessed 10 January 2021).

2. Lewis, A. and McKone, D. (2016). "So many M\&A deals fail because companies overlook this simple strategy," Harvard Business Review Digital Articles, https://hbr.org/2016/05/so-many-ma-deals-fail-because-companies-overlook-thissimple-strategy (accessed 2 January 2021).

3. Massoudi, A., Espinoza, J. and Smith, R. (2019). "Bayer's Monsanto acquisition leaves it with a toxic legacy," Financial Times.

https://www.ft.com/content/587250aa-b96d-11e9-8a88-aa6628ac896c (accessed 3 January 2021).

4. Brower, D., Fontanella-Khan, J., Rennison, J. and Raval, A. (2020). "Occidental Petroleum slashes dividend as oil price rout bites," Financial Times. https://www.ft.com/content/96c3225c-62e7-11ea-a6cd-df28cc3c6a68 (accessed 3 January 2021).

5. Faelten, A., Driessen, M. and Moeller, S. (2016), Why Deals Fail and How to Rescue Them: M\&A Lessons for Business Success, Profile Books, London, UK.

6. Deloitte. (2019). "The state of the deal: M\&A trends 2019," Deloitte. https://www2.deloitte.com/content/dam/Deloitte/us/Documents/mergersacqisitions/us-mergers-acquisitions-trends-2019-report.pdf (accessed 2 January 2021). 
7. Powell, J. (2020). "Is this the worst M\&A deal of the 2010s?" Financial Times. https://www.ft.com/content/696fbc05-7dae-4eaa-b5be-548589bd29b4 (accessed 2 January 2021).

8. Lex, O. (2020). "Occidental Petroleum: dash for cash," Financial Times. https://www.ft.com/content/35f1283d-af67-4d55-886f-650f38d4e6f7 (accessed 2 January 2021).

9. Trainer, D. (2016). "Why companies overpay for acquisitions," Forbes. https://www.forbes.com/sites/greatspeculations/2016/07/21/why-companiesoverpay-for-acquisitions/\#445b361044c6 (accessed 2 January 2021).

10. Smit, H. and Lovallo, D. (2014). "Creating more accurate acquisition valuations," MIT Sloan Management Review, Vol. 56 No. 1, pp. 63-71.

11.Zollo, M. and Singh, H. (2007), "Deliberate learning in corporate acquisitions: post-acquisition strategies and integration capability in U.S. bank mergers," Strategic Management Journal, Vol. 25 No. 13, pp. 1233-1256.

12. Galpin, T.J. (2018), "Reap exceptional value from M\&A: manage it as a core competence," Strategy \& Leadership, Vol. 46 No. 5, pp. 17-25.

13. Galpin, T.J. and Herndon, M. (2014), The Complete Guide to Mergers \& Acquisitions: Process Tools to Support M\&A Integration at Every Level, Third Edition, John Wiley and Sons, San Francisco, CA.

14. Galpin, T.J. (2019). "Avoid M\&A assimilation heartburn: an actionable model for cultural due diligence and integration," Strategy \& Leadership, Vol. 47 No. 4, pp. 20-25.

15. Kuchler, H. (2018). "Eventbrite: building a business through acquisitions," Financial Times. https://www.ft.com/content/eab30b96-51d9-11e8-b24ecad6aa67e23e (accessed 4 January 2021).

16. Galpin, T.J. (2020), Winning at the Acquisition Game: Tools, templates, and best practices across the M\&A process, Oxford University Press, Oxford, UK. 


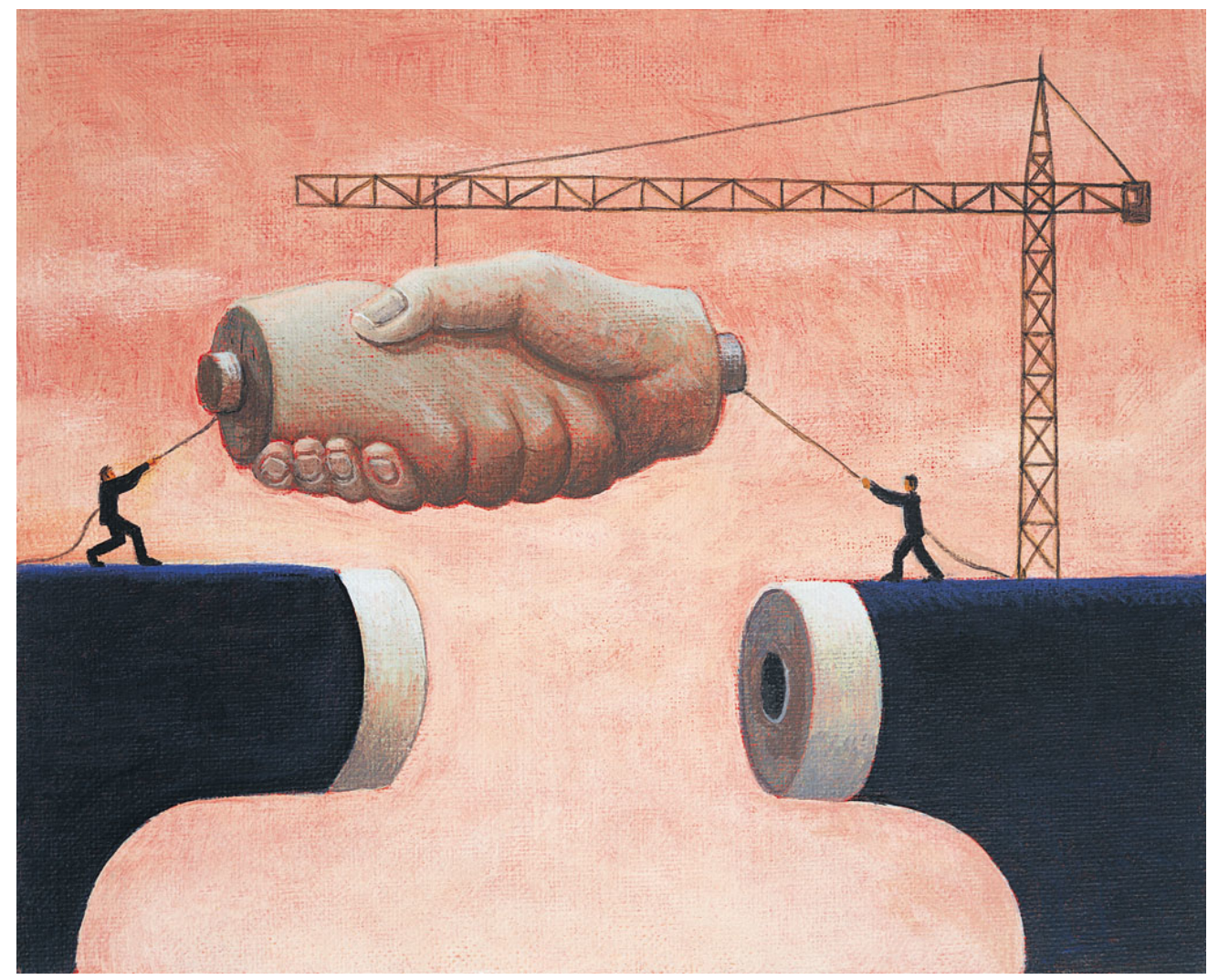

Stock art. Use as illustration 56044 Think business $361 \times 293 \mathrm{~mm}(72 \times 72 \mathrm{DPI})$ 